\title{
Impact Of Computer Based Share Market Simulations On Learning: A Link Between Self-Efficacy And Understanding
}

F. Douglas Foster, (E-mail: fd.foster@unsw.edu.au), University of New South Wales Shirley Gregor, (E-mail: shirley.gregor@anu.edu.au), Australian National University Richard Heaney, (E-mail: richard.heaney@rmit.edu.au), RMIT University William Northcott, (E-mail: w.northcott@unsw.edu.au), University of New South Wales Terry O’Neill, (E-mail: terry.oneill@anu.edu.au), Australian National University Alex Richardson, (E-mail: alex.richardson@anu.edu.au), Australian National University Emma Welch, (E-mail: emma.welch@anu.edu.au), Australian National University Robert Wood, (E-mail: r.wood@econ.usyd.edu.au), University of Sydney

\begin{abstract}
While the literature supports the use of share market simulation as an educational tool we analyse the impact of a share market simulation on student self-efficacy and understanding. We find evidence of a statistically significant increase in self-efficacy through the use of the educational simulation. We also find that while self-efficacy at the start of the simulation is positively correlated with the level of self-efficacy at the end, the final level of understanding attained is positively related to both self-efficacy and the level of understanding that existed at the beginning of the simulation.
\end{abstract}

\section{INTRODUCTION}

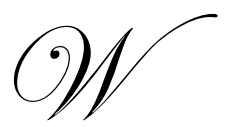

hile there appears to be wide agreement that classroom simulations are a useful teaching aid there is little written on the impact of share market simulations on the participants. Because trading simulations commonly used to familiarize students with financial markets, this study makes an important contribution to our understanding of finance education. We focus on the impact of simulated markets on student self-efficacy and understanding throughout the task. Our share market simulation is used to introduce first year undergraduate students to basic trading procedures and provide a simple, yet rich, example of how information influences market prices.

We consider two measures of student performance through the computer simulation experience. First, we look at their overall understanding of the technical aspects of the learning case. Second we look at self-efficacy, roughly their confidence or comfort with the material before and after the simulation experience.

Our analysis is based on data collected through a series of questionnaires. An initial questionnaire is administered to measure participant self-efficacy and understanding prior to taking part in the simulation with the follow-up questionnaire administered to assess the impact of the share trading simulation on both self-efficacy and understanding. The simulation consisted of 20-30 minutes trading using a simple limit-order based share market developed by OS Financial Trading Systems (O'Brien and Srivastava, 1991).

We find a statistically significant increase in self-efficacy after the trading session, although the observed increase in understanding is not statistically significant. Further, we find that the level of prior self-efficacy was positively correlated with self-efficacy after the simulation. Finally, we note that the level of understanding after the 
simulation was positively related to both the level of understanding and the level of self-efficacy that existed before the simulation took place. A brief literature review and hypothesis development follows. The data is described in Section 3 and section 4 is devoted to discussion and conclusions.

\section{LITERATURE REVIEW AND HYPOTHESIS DEVELOPMENT}

The benefits from the use of simulations in a classroom are often noted in the literature (Ball and Holt, 1998, Foster et al, 2004, Frank, 1997, Helliar et al, 2000, Kagan et al, 1995, Lawrence, 1994, and Sachdeva, 1989) and the more modern simulations seem to be gathering respect both from industry and from educational institutions (Cerrahoglu, 2003, Sanford, 2000a and 2000b). There are many types of simulation used in economics and finance education ranging from the market-based simulation (like that used in this study) to more generic web based offerings (Berentson, 2001, Cady, 2002, Dabaie and DeSmidt, 2000). While special purpose educator developed simulations provide a focused learning experience, the greater workload imposed in terms of development and maintenance is an important consideration (McClatchey and Kuhlemeyer, 2000). Given the resource constraints faced by most educational institutions relatively low cost packaged systems, like the one used for our simulation, could make an important contribution to undergraduate education.

Simulations differ in terms of realism and also in terms of the control that can be exercised over the learning experience. Wood and Bailey (1985) discuss the greater levels of realism that simulations provide although they also argue that the instructor may have less control over what is happening in more complex simulations. Further, while more realistic trading environments can be costly to set up and run (Alexander et al., 2001) this need not be the case if a more selective approach is taken (Alonzi et al, 2000, Angel, 1994, Cooper and Grinder, 1997, Dougherty and Subramanian, 1995, McClatchey and Kuhlemeyer, 2000). We use a share trading market simulation in the Australian National University (ANU) introductory finance classes to provide participants with insights into trading and price discovery.

We focus on the impact of the simulation on participant self-efficacy (Bandura, 1978) and understanding. Self-efficacy (Bandura, 1978) has proven to be an important factor in explaining individual success in learning and Chan et al (2004), Christoph et al (1998), Hayashi et al (2004) and Tan and Zhao (2003) expand this notion to different learning scenarios. Self-efficacy is defined as, "the belief in one's capabilities to organize and execute sources of action required to manage prospective situations," (Bandura (1986)). Generally the greater the self-efficacy about a task the better the participant does at that task, whether this be associated with an individual's receptiveness to undertake further technical education or training, the use of e-learning systems or the adoption of internet banking. The level of self-efficacy that an individual feels about their ability to complete a task can have a considerable impact on their actual performance in the task. Bandura (1986) suggests that self-efficacy will tend to increase over time as the participants gain greater exposure to the task at hand. This gives rise to our first hypothesis.

\section{Hypothesis 1:}

Null: There is no change in self-efficacy arising from the simulation. Alternate: Self-efficacy increases with completion of the simulation.

If the simulation is to be worthwhile then it is expected that there will be an increase in the level of understanding exhibited by the participants who take part in the simulation. This gives rise to the second of the hypotheses.

\section{Hypothesis 2:}

Null: There is no change in understanding arising from the simulation. Alternate: Understanding increases with completion of the simulation. 
Christoph et al (1998) argue that self-efficacy increases the effectiveness of training and so we hypothesize that there will be a positive relationship between understanding and the level of self-efficacy that the participants exhibit.

\section{Hypothesis 3:}

Null: There is no relation between understanding and self-efficacy

Alternate: Understanding is positively related with self-efficacy prior to the simulation.

\section{DATA COLLECTION}

Our study was conducted using a group of students enrolled in a first year finance course. The majority of the students are aged from 19 to 20 years of age and there is a fairly even mix of male and female students in the class. There is considerable variation in the prior experience in the group as is common with first year undergraduate students.

All participants in the undergraduate course were expected, although not required, to complete the one-hour tutorial that included the share market simulation. There were 273 participants who took part in the simulation and attempted questionnaires, which was run during the tutorial periods immediately following the share markets lecture. To prepare students for the simulation the last 15 minutes of the share markets lecture was devoted to issues in valuation and trading relevant to the simulation.

The simulation tutorial was broken into four parts, review of the valuation and trading issues necessary for the simulation, completion of the sections 1, 2 and 3 of the questionnaire (see Appendix 3), share market simulation, and completion of the sections 4 and 5 of the questionnaire (see Appendix 3). The questionnaire sections consist of a series of questions to measure the participant's self-efficacy and understanding of valuation and trading. Completion of the questionnaire was optional and students were required to sign a consent form before their questionnaires were collected. Hence, all students were able to participate in the learning task, but we only have data from students who provided written consent to have their responses made part of this study.

Virtually all consenting students completed all self-efficacy questions, although the response rate for the more taxing understanding questions was less than 50\%. For the final set of questionnaires the response rates dropped to less than 20\%. Perhaps this is to be expected given that the participants are first year undergraduate students. These students enter the course with a wide range of abilities, skills and expectations and they have little formal knowledge of the time value of money, share valuation or the way that shares are traded in the stock market prior to this course.

The self-efficacy questions focus on the level of confidence that the participants report about their ability to trade and their understanding of share valuation. We ask the participants how confident they are about five tasks with responses coded over a 5-point likert scale ranging from 1 (not at all confident) to 3 (moderately confident) to a maximum of 5 (totally confident). The five tasks are "pricing a share", "setting a bid", "setting an ask", "buying" and "selling" and these account for parts a) to e) of sections 2 and 4 of the questionnaire. The Cronbach alpha for the five questions of section 2 (answered before the simulation) is 0.92 . The corresponding five questions of section 4 were completed after the simulation with a Cronbach alpha of 0.94 .

The sections 3 and 5 of the questionnaire deal with participant understanding of share valuation and trading and focus on the valuation and trading of just one of the two traded shares (ABC, see Appendix 2 for more details). The same seven questions appear in both sections 3 and 5 of the questionnaire (note that question 1 has 4 sub-queries). The first question these sections is concerned with the dividend information that is provided to each participant in the simulation. The second and third questions focus on the ability of participants to identify share price limits. Question 4 examines the relation between first period dividends and the dividends that are paid in the following period. Finally, questions 5, 6 and 7 test whether the participant understands the bid and ask prices and how market prices are set. Graded responses to each question were recorded and the Cronback alpha for sections 3 and 5 were 0.50 and 0.45 
respectively. Question 6, in particular, showed a dramatic increase in understanding with completion of the simulation, increasing from $31 \%$ correct before the simulation to $70 \%$ correct after the simulation. Nevertheless, even when this question is dropped from the analysis the Cronback alpha does not improve much (from 0.50 to 0.58 before the simulation and 0.45 to 0.42 after the simulation respectively).

\section{RESULTS, DISCUSSION AND CONCLUSION}

The following discussion concentrates on the impact of the simulation on the level of self-efficacy and the level of understanding exhibited by the participants before and after the simulation. Initially t-tests are conducted to test for an increase in self-efficacy and in understanding that might arise from taking part in the simulation. The second part of the analysis involves the use of correlation and regression in analysis of the relations that exist between the level of participant self-efficacy and the level of participant understanding.

\section{Self-Efficacy}

There are five questions that focus on self-efficacy. We test for a statistically significant difference in the level of self-efficacy that arises from taking part in the share market simulation and t-tests are conducted for each of the five questions and these are reported in Table 1 along with frequency distributions and percentages. The selfefficacy responses in section 2 and section 4 suggest an increase in self-efficacy after the simulation and this is shown to be statistically significant in Panel $\mathrm{C}$ of Table 1 . Thus we are able to reject the null under Hypothesis 1 , in favour of the alternative hypothesis that self-efficacy increases with taking part in the simulation.

Table 1: Self-Efficacy

Panel A: Frequencies For Self-Efficacy In Trading Questions

\begin{tabular}{|c|c|c|c|c|c|c|c|c|c|}
\hline Section, part & Not sure & $\begin{array}{l}\text { Not at all } \\
\text { confident }\end{array}$ & $\begin{array}{c}\text { Slightly } \\
\text { confident }\end{array}$ & $\begin{array}{c}\text { Mod'ly } \\
\text { confident }\end{array}$ & $\begin{array}{c}\text { Very } \\
\text { confident }\end{array}$ & $\begin{array}{c}\text { Totally } \\
\text { confident }\end{array}$ & Total & Missing & Total \\
\hline \multicolumn{10}{|l|}{ Before } \\
\hline $2, a$ & 26 & 44 & 71 & 92 & 25 & 8 & 266 & 7 & 273 \\
\hline $2, \mathrm{~b}$ & 18 & 37 & 66 & 89 & 45 & 11 & 266 & 7 & 273 \\
\hline $2, \mathrm{c}$ & 21 & 36 & 61 & 93 & 42 & 11 & 264 & 9 & 273 \\
\hline $2, \mathrm{~d}$ & 13 & 29 & 66 & 99 & 45 & 14 & 266 & 7 & 273 \\
\hline $2, \mathrm{e}$ & 14 & 30 & 65 & 97 & 51 & 9 & 266 & 7 & 273 \\
\hline \multicolumn{10}{|l|}{ After } \\
\hline $4, \mathrm{a}$ & 14 & 24 & 43 & 101 & 54 & 19 & 255 & 18 & 273 \\
\hline $4, b$ & 12 & 13 & 45 & 96 & 60 & 29 & 255 & 18 & 273 \\
\hline $4, \mathrm{c}$ & 14 & 16 & 39 & 94 & 60 & 32 & 255 & 18 & 273 \\
\hline $4, \mathrm{~d}$ & 13 & 13 & 37 & 89 & 70 & 33 & 255 & 18 & 273 \\
\hline $4, \mathrm{e}$ & 15 & 11 & 43 & 82 & 70 & 34 & 255 & 18 & 273 \\
\hline
\end{tabular}

Panel B: Response Percentages For Self-Efficacy In Trading Questions

\begin{tabular}{cccccccc}
\hline Section, part & Not sure & $\begin{array}{c}\text { Not at all } \\
\text { confident }\end{array}$ & $\begin{array}{c}\text { Slightly } \\
\text { confident }\end{array}$ & $\begin{array}{c}\text { Mod'ly } \\
\text { confident }\end{array}$ & $\begin{array}{c}\text { Very } \\
\text { confident }\end{array}$ & $\begin{array}{c}\text { Totally } \\
\text { confident }\end{array}$ & Number \\
\hline $\begin{array}{c}\text { Before } \\
\text { 2,a }\end{array}$ & 9.77 & 16.54 & 26.69 & 34.59 & 9.40 & 3.01 & 266 \\
2,b & 6.77 & 13.91 & 24.81 & 33.46 & 16.92 & 4.14 & 266 \\
2,c & 7.95 & 13.64 & 23.11 & 35.23 & 15.91 & 4.17 & 264 \\
2,d & 4.89 & 10.90 & 24.81 & 37.22 & 16.92 & 5.26 & 266 \\
2,e & 5.26 & 11.28 & 24.44 & 36.47 & 19.17 & 3.38 & 266 \\
\hline
\end{tabular}




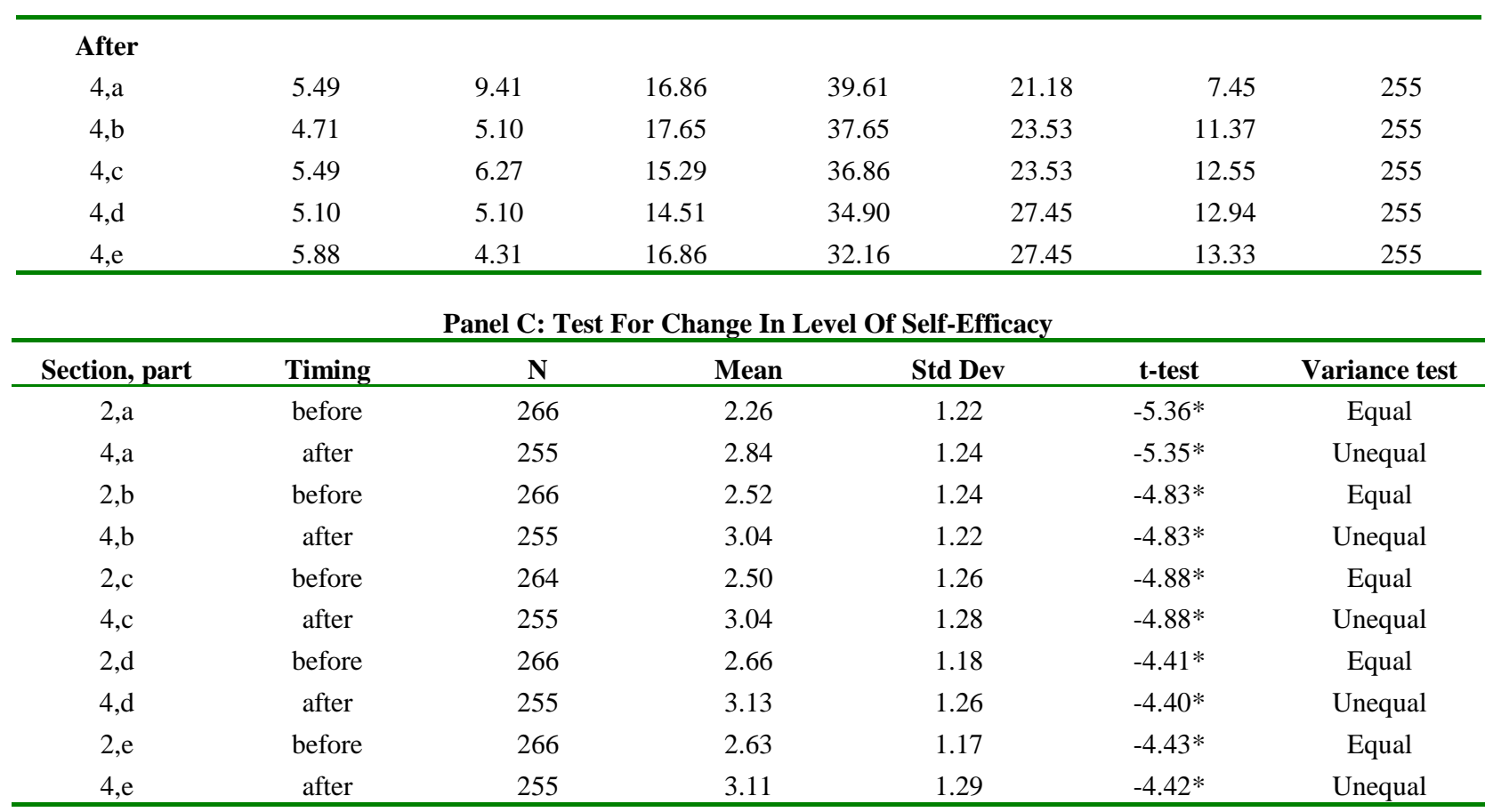

Note: Section, part $=$ reference to question in the questionnaire (see Appendix 3). Timing = before or after the simulation took place. Mean $=$ average score for the particular question. Std. Dev. $=$ standard deviation of the participant responses. $t$-test $=$ test of the difference in the response before the simulation (B) and the response after the simulation (A) (B minus A). * Statistically significant at the $5 \%$ level of significance.

\section{Understanding}

While the change in the level of understanding is not the critical factor in this analysis it is important to get a sense of the impact of the simulation on the level of understanding. It is difficult to accurately gauge understanding (as was indicated by the Cronbach alpha for our series of questions) but nevertheless it is important to get a sense of the impact on participant understanding that is gained from taking part in the simulation. It may be that a longer period of time in simulation would result in more dramatic changes in understanding.

The participants generally show a reasonable understanding of the task. More than 50\% of the participants provide the correct response for the majority of the questions. For example, seven out of ten of the questions were answered correctly by more than $50 \%$ of the participants before the simulation, with more than $50 \%$ of the participants correctly answering nine out of ten of the questions after the simulation. The level of understanding generally increased after the simulation although it is rarely statistically significantly different from the level exhibited before the simulation. The one exception is the response to the question in subsection 6 of sections 3 and 5 (Table 2) where the simulation results in a dramatic improvement in understanding. This question referred to the impact of an ask price. Students often have problems with conceptualising how bid and ask prices work and it may well be that trading helped students to better understand how limit orders work in practise. 
Table 2: Understanding

Panel A: Frequencies For Understanding In Trading Questions

\begin{tabular}{|c|c|c|c|c|c|}
\hline Section, part & Incorrect Answer & Correct Answer & Total & Missing & Total \\
\hline \multicolumn{6}{|l|}{ Before } \\
\hline $3,1, \mathrm{a}$ & 44 & 147 & 191 & 82 & 273 \\
\hline $3,1, b$ & 41 & 140 & 181 & 92 & 273 \\
\hline $3,1, \mathrm{c}$ & 79 & 73 & 152 & 121 & 273 \\
\hline $3,1, \mathrm{~d}$ & 46 & 106 & 152 & 121 & 273 \\
\hline 3,2 & 39 & 126 & 165 & 108 & 273 \\
\hline 3,3 & 92 & 70 & 162 & 111 & 273 \\
\hline 3,4 & 53 & 94 & 147 & 126 & 273 \\
\hline 3,5 & 70 & 84 & 154 & 119 & 273 \\
\hline 3,6 & 82 & 37 & 119 & 154 & 273 \\
\hline 3,7 & 39 & 82 & 121 & 152 & 273 \\
\hline \multicolumn{6}{|l|}{ After } \\
\hline $5,1, \mathrm{a}$ & 26 & 127 & 153 & 120 & 273 \\
\hline $5,1, \mathrm{~b}$ & 25 & 123 & 148 & 125 & 273 \\
\hline $5,1, \mathrm{c}$ & 66 & 68 & 134 & 139 & 273 \\
\hline $5,1, \mathrm{~d}$ & 36 & 99 & 135 & 138 & 273 \\
\hline 5,2 & 32 & 114 & 146 & 127 & 273 \\
\hline 5,3 & 81 & 64 & 145 & 128 & 273 \\
\hline 5,4 & 54 & 80 & 134 & 139 & 273 \\
\hline 5,5 & 62 & 76 & 138 & 135 & 273 \\
\hline 5,6 & 35 & 80 & 115 & 158 & 273 \\
\hline 5,7 & 36 & 83 & 119 & 154 & 273 \\
\hline
\end{tabular}

Panel B: Response Percentages for Understanding in Trading Questions

\begin{tabular}{cccc}
\hline Section, part & Incorrect Answer & Correct Answer & Number \\
\hline Before & & & \\
\hline $3,1, \mathrm{a}$ & 23.04 & 76.96 & 191.00 \\
$3,1, \mathrm{~b}$ & 22.65 & 77.35 & 181.00 \\
$3,1, \mathrm{c}$ & 51.97 & 48.03 & 152.00 \\
$3,1, \mathrm{~d}$ & 30.26 & 69.74 & 152.00 \\
3,2 & 23.64 & 76.36 & 165.00 \\
3,3 & 56.79 & 43.21 & 162.00 \\
3,4 & 36.05 & 63.95 & 147.00 \\
3,5 & 45.45 & 54.55 & 154.00 \\
3,6 & 68.91 & 31.09 & 119.00 \\
3,7 & 32.23 & 67.77 & 121.00 \\
\hline
\end{tabular}




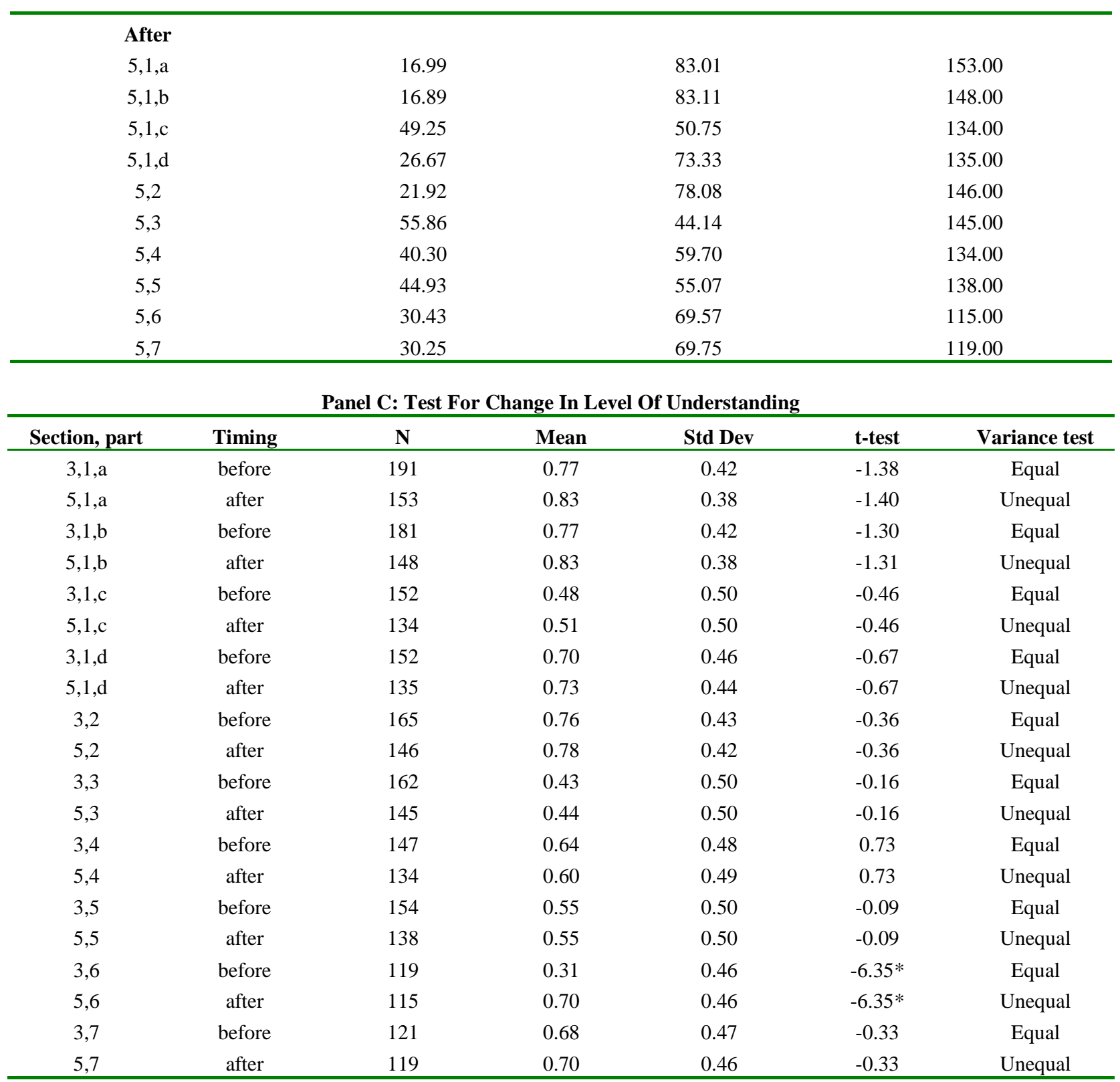

Note: Section, part = reference to question in the questionnaire (Appendix 1). Timing = before or after the simulation took place. Mean $=$ average score for the particular question. Std. Dev. $=$ standard deviation of the participant responses. t-test $=$ test of the difference in the response before the simulation (B) and the response after the simulation (A) (B minus A). * Statistically significant at the $5 \%$ level of significance.

Although there is only one statistically significant t-test that supports the importance of the simulation for understanding, in all but one case there was an increase in the average level of understanding. Further, there was an increase in the number of questions answered correctly by a majority of respondents with seven of the questions correctly answered prior to the simulation compared with nine questions correctly answered after the simulation. Nevertheless, we are unable to reject the null for Hypothesis 2. 


\section{Correlation And Regression Analysis}

We calculate the average response for the self-efficacy questions and for the understanding questions and estimate correlations between these averages using Spearman's Rho correlation coefficients. There is a strong positive correlation between the level of self-efficacy before the simulation and after the simulation, consistent with Hypothesis 1 . There is also a strong positive correlation between the level of understanding before the simulation and after the simulation, consistent with Hypothesis 2. The link between self-efficacy and understanding is quite interesting and appears to be asymmetric in nature. While both the level of self-efficacy and the level of understanding have a positive impact on the level of understanding at the end of the simulation, consistent with Hypothesis 3 , there is no evidence that the level of understanding at the beginning of the simulation has an impact on the level of self-efficacy exhibited at completion of the simulation.

Table 3

Spearman's Rho Correlations

\begin{tabular}{cccccc}
\hline & & AVGCONFA & AVGCONFB & AVGUNDA & \multicolumn{2}{c}{ AVGUNDB } \\
\hline AVGCONFA & Correlation & 1.00 & $0.62^{*}$ & $0.25^{*}$ & 0.13 \\
& & & $(0.00)$ & $(0.02)$ & $(0.26)$ \\
AVGCONFB & Number & 255 & 249 & 90 & 77 \\
& Correlation & $0.62^{*}$ & 1.00 & $0.31^{*}$ & $0.23^{*}$ \\
& & $(0.00)$ & & $(0.00)$ & $(0.04)$ \\
AVGUNDA & Number & 249 & 264 & 90 & 80 \\
& Correlation & $0.25^{*}$ & $0.31^{*}$ & 1.00 & $0.73^{*}$ \\
& & $(0.02)$ & $(0.00)$ & & $(0.00)$ \\
AVGUNDB & Number & 90 & 90 & 90 & 60 \\
& Correlation & 0.13 & $0.23^{*}$ & $0.73^{*}$ & 1.00 \\
& & $(0.26)$ & $(0.04)$ & $(0.00)$ & 80 \\
\hline
\end{tabular}

Note:* Statistically significant at the 5\% level of significance. AVGCONFB is the average response for the set of five questions concerning self-efficacy about the use of the simulation completed before trading commenced, AVGCONFA is the average response for the set of five questions concerning self-efficacy about the use of the simulation completed after trading commenced, AVGUNDB is the average response for the set of ten questions concerning understanding of the underlying asset valuation process completed before trading commenced, AVGUNDB is the average response for the set of ten questions concerning understanding of the underlying asset valuation process completed after trading commenced. Number is the number of observations available for the variable. The number in parentheses, below the correlation coefficient, is the probability that the correlation coefficient is equal to zero.

We use ordinary least squares regression to determine the relative importance of before simulation selfefficacy and understanding in explaining post simulation self-efficacy and understanding. We regress the level of self-efficacy at the end of the simulation on the level of self-efficacy at the beginning of the simulation as well as the level of understanding at both the beginning and the end of the simulation and report the results in Panel A of Table 4. We find that only the level of self-efficacy at the beginning of the simulation is statistically significantly correlated with self-efficacy at the end of the period. The level of understanding measured by our questionnaire plays no role in explaining the level of self-efficacy that participants exhibit at the end of trading. 
Table 4

Relation Between Self-Efficacy And Understanding Panel A: Dependent Variable: AVGCONFA

\begin{tabular}{ccc}
\hline & Coefficient & Significance \\
\hline (Constant) & $5.300^{*}$ & 0.02 \\
AVGUNDB & 0.516 & 0.17 \\
AVGUNDA & -0.614 & 0.17 \\
AVGCONFB & $0.899^{*}$ & 0.00 \\
R Square & 0.601 & \\
F & $28.136^{*}$ & 0.00 \\
\hline
\end{tabular}

Panel B: Dependent Variable: AVGUNDA

\begin{tabular}{ccc}
\hline & Coefficient & Significance \\
\hline (Constant) & $2.144^{*}$ & 0.00 \\
AVGUNDB & $0.597^{*}$ & 0.00 \\
AVGCONFB & $0.154^{*}$ & 0.00 \\
AVGCONFA & -0.054 & 0.17 \\
R Square & 0.599 & 0.00 \\
F & $27.831^{*}$ & \\
\hline
\end{tabular}

Note:* Statistically significant at the $5 \%$ level of significance. There were 60 observations, out of a maximum of 273 observations, with a complete set of values for each of the average self-efficacy measures, AVGCONFB and AVGCONFA, and the average understanding measures, AVGUNDB and AVGUNDA.

Perhaps the more interesting finding is the relation between taking part in the simulation and the impact on understanding. The results from this analysis are reported in Panel B of Table 4. It is clear that both the level of understanding and the level of self-efficacy at the start of the simulation have an important impact on the level of understanding at the end of the simulation. It appears that both the initial level of understanding and self-efficacy of the participant drive understanding. Hence, educators interested in using simulation in class may want to consider expanding their preparation efforts to build not only initial understanding but initial self-efficacy. We suspect that selfefficacy is often not explicitly considered in the design of preparation materials for students in lab and simulation settings.

\section{CONCLUSION}

It would appear that teachers who use simulations for educational purposes need to pay considerable attention to introducing the participants to the basic rules that drive the simulation and to discussing the nature of the simulation before participants are asked to take part. It is important that students come into the simulation with some basic understanding of the share market trading as well as some acceptable level of self-efficacy about what they are doing. We want material to be clear to students, but also want them to be comfortable enough with the proposed task that they are able to learn effectively.

Insights from our 20-30 minute simulation include increased self-efficacy and some increase in understanding, and the realisation that understanding and self-efficacy are linked. The level of student self-efficacy and understanding at the beginning of the simulation were positively related with the level of understanding at the end of the simulation. If our objective is to increase understanding then it is important to focus on tasks that raise student confidence as well as ensuring that students have sufficient prior knowledge to allow them to take an active role in the simulation.

There is evidence of increased levels of understanding with virtually all of the understanding questions although there is little statistically significant difference evident. Perhaps 20-30 minutes is not sufficient for students 
to develop a greater understanding of the more important concepts that the simulation can convey. It would also be interesting to see the impact of increased trading time on self-efficacy and understanding.

We would like to thank the Australian National University (ANU) for allowing the research group to work with the first year finance students and we acknowledge the Australian Research Council (ARC) for support through a Discovery-Project grant (DP0343994).

\section{REFERENCES}

1. Alexander, J. C., C. C. Heck, and R. B. McElreath, 2001, A Guide to Building a University Trading Room, Financial Services Review, 10, 209-220.

2. Alonzi, P., D. R. Lange, and B. J. Simkins, 2000, An Innovative Approach in Teaching Futures: A Participatory Futures Trading Simulation, Financial Practice and Education, 10, 228-238.

3. Angel, J. J., 1994, The Broker Game: An Enjoyable Way to Introduce Students to Financial Markets (and Learn their Names), Financial Practice and Education, 4, 61-64.

4. Ball, S. B. and C. A. Holt, 1998, Classroom Games: Speculation and Bubbles in an Asset Market, Journal of Economic Perspectives, 12, 207-218.

5. Bandura, A., 1978, The Self-System in Reciprocal Determinism, American Psychologist, 33, 344-358.

6. Bandura, A., 1986, Social Foundation of Thought and Action: A Social Cognitive Theory, Englewood Cliffs, NJ, Prentice-Hall.

7. Berentson, B., 2001, Best of the Web, Forbes, 167, 80-2.

8. Cady, D., 2002, It May be Play Money, But this Guy’s Hooked, Japan Inc., 29, 20-21.

9. Cerrahoglu, B., 2003, A Web-Based Futures Trading Simulation Program with Pretend Money, Journal of Alternative Investments, 6, 95-96.

10. Chan, S.-C. and M.-T. Lu, 2004, Understanding Internet Banking Adoption and Use Behavior: A Hong Kong Perspective, Journal of Global Information Management, 12, 21-43.

11. Christoph, R. T., G. A. Schoenfeld, Jr., and J. W. Tansky, 1998, Overcoming Barriers to Training Utilising Technology: The Influence of Self-Efficacy Factors on Multimedia-Based Training Receptiveness, Human Resource Development Quarterly, 9, 25-38.

12. Cooper, D. W. and B. Grinder, 1997, Introducing Option Pricing Theory with a Classroom Game, Financial Practice and Education, 7, 95-102.

13. Dabaie, M. and B. DeSmidt, Bisys Upgrades Nasdaq Trade Simulator for Classroom Use, Securities Industry News, 12,9 .

14. Dougherty, K. J. and V. Subramanian, 1995, Building a Brokerage Firm: Experience form Stock Market Games, Financial Practice and Education, 5, 45-49.

15. Frank, B., 1997, The Impact of Classroom Experiments on the Learning of Economics: An Empirical Investigation, Economic Inquiry, 35, 763-769.

16. Foster, F. D., S. Gregor, R. A. Heaney, T. O’Neill, A. Richardson, and R. E. Wood, 2004, Market Games in Finance Education, Journal of College Teaching and Learning, 1, 5, 81-92.

17. Hayashi, A., C. Chen, T. Ryan, and J. Wu, 2004, The Role of Social Presence and Moderating Role of Computer Self-Efficacy in Predicting the Continuance Usage of E-Learning Systems, Journal of Information Systems Education, 15, 139-154.

18. Helliar, C.V., R. Michaelson, D. M. Power, and C. D. Sinclair, 2000. Using a Portfolio Management Game (Finesse) to Teach Finance, Accounting Education, 9, 37-51.

19. Kagan, G., H. Mayo, and R. Stout, 1995, Risk-Adjusted Returns and Stock Market Games, Journal of Economic Education, 26, 39-50.

20. Lawrence, E., C., 1994, Financial Innovation: The Case of Student Investment Funds at United State Universities, Financial Practice and Education, 4, 47-53.

21. McClatchey, C. A. and G. A. Kuhlemeyer, 2000, Incorporating Stock Market Games into the Classroom: A Survey of Faculty Teaching Investments, Financial Practice and Education, 10, 208-221.

22. O'Brien, J. and S. Srivastava, 1991 Dynamic Stock Markets With Multiple Assets: An Experimental Analysis, Journal of Finance, 46, 1811-1838. 
23. Sachdeva, D., 1989 Psychology of Computer Use: XI. Students' Attitudes Toward Use of ComputerSimulation Games in Teaching Business Finance, Psychological Reports, 64, 1195-1198.

24. Sanford, W., 2000a, Trading Boot Camps, Traders Magazine, 13, 32-36.

25. Sanford, W., 2000b, Hey! Are You Ready for Some Trading? Traders Magazine, 13, 42-43.

26. Tan, H. H. and B. Zhao, 2003, Individual-and Perceived Contextual-Level Antecedents of Individual Technical Information Inquiry in Organizations, Journal of Psychology, 137, 597-621.

27. Wood, R. E. and T. S. Bailey, 1985, Some Unanswered Questions about Goal Effects: A Recommended Change in Research Methods, Australian Journal of Management, 10, 61-76.

\section{APPENDIX 1 - OVERVIEW OF THE SHARE MARKET SIMULATION}

The "market efficiency" simulation used in this study is the simplest of a comprehensive set of market simulations supplied by OS Financial Trading Systems. We use only two shares throughout the study, although the software can deal with more shares. There are few limitations on the number of participants although hardware constraints will ultimately have an impact on the performance.

Trading occurs over two periods and each stock pays a dividend at the end of every trading period according to a set payoff plan (described in more detail in Appendix 2). While there is a facility for discounting cash flows we set the discount rate to zero for simplicity. Hence the share value is equal to the sum of the expected dividend payments. Market participants have limited information about the dividend payments and so they must use the information given to them as well as the information reflected in the market's share prices to determine the value of the shares. The two stocks have either 3 or 4 dividend states each period, with all states equally likely. Traders are not told which state will occur. Rather, they are told one state that will not occur, and they must infer other information from watching the share prices in the market. The information is consistent between periods (they receive the same hint). The hints given out to the entire class allows easy identification of the share value, while the hint to any particular student leaves them with considerable uncertainty as to the share value. The structure of the payoffs is relatively simple, but the inference problem facing the students is quite demanding.

The market software allows students to buy and sell from each other through a centralized limit order book. Any student can submit bids and asks orders (indications of a willingness to by or sell, respectively) or buy or sell to the market. Bid and ask orders require the submission of a price (a bid indicates a willingness to buy at or below the bid price, and ask is a willingness to sell at or above the ask price) and a quantity of shares that they are willing to trade (the depth of the quote). Market orders require only a number of shares as the price is determined by the available bid or ask order. All students can see the best bid and ask as well as the limit order book details of pending orders in the market. Students are endowed with cash and shares at the start of trading and we allow them to borrow either additional shares or funds during trading. At the end of trading all dividends are paid and the students cash holdings are reported on their screen (as well as the minimum, maximum and average cash holdings of all traders in same tutorial).

The tutorial period spanned one hour with a 15-minute lecture on the simulation, about 5 minutes completing the initial questionnaire, about half an hour for trading and a final 5-minute period for completion of the final questionnaire. The trading period is split into trials, with each trial consisting of two 5-minute trading periods, period 1 and period 2. There were usually about two to three trading trials in a one-hour tutorial. More information on the trading software can be found in Foster, et al (2004) or at www.ftsnet.com

\section{APPENDIX 2 - DIVIDEND DETERMINATION AND SHARE VALUATION}

There are two trading periods and the dividend payments are paid at the end of each period. Participants do not have full information concerning the dividend payments but instead each participant is given partial information about the dividend payment occurring at the end of period 1 and period 2. The following table describes the equally likely events affecting each firm, and the dividends paid at the end of period 1. 


\begin{tabular}{llc}
\hline Firm ABC & & Dividend \\
\hline Event x & Poor economic conditions, labour strike & 0 \\
Event y & Poor economic conditions, no strike & 12 \\
Event $\mathrm{z}$ & Fair economic conditions, good labour relations & 24 \\
\hline Firm CRA & & Dividend \\
\hline Event $\mathrm{w}$ & Poor economic conditions, labour strike & 0 \\
Event x & Poor economic conditions, no strike & 12 \\
Event y & Fair economic conditions, no strike & 12 \\
Event $\mathrm{z}$ & Fair economic conditions, good labour relations & 24 \\
\hline
\end{tabular}

These events are translated to dollar dividends as follows (dividends paid at the end of period 2 depend on both the period 1 event and the period 2 event).

Firm ABC

\begin{tabular}{cccc}
\hline \multicolumn{2}{c}{ Period 1 Event } & \multicolumn{2}{c}{ Period 2 Event } \\
\hline Period 2 Col & $\mathrm{x}$ & $\mathrm{y}$ & $\mathrm{Z}$ \\
Period 1 Row & & & \\
$\mathrm{x}$ & 0,0 & 0,0 & 0,12 \\
$\mathrm{y}$ & 12,0 & 12,12 & 12,24 \\
$\mathrm{z}$ & 24,12 & 24,12 & 24,24 \\
\hline
\end{tabular}

Firm CRA

\begin{tabular}{ccccc}
\hline Period 1 Event & \multicolumn{5}{c}{ Period 2 Event } \\
\hline $\begin{array}{c}\text { Period 2 Col } \\
\text { Period 1 Row }\end{array}$ & $\mathrm{w}$ & $\mathrm{x}$ & $\mathrm{y}$ & $\mathrm{z}$ \\
w & 0,8 & 0,8 & 0,12 & 0,18 \\
X & 12,8 & 12,8 & 12,12 & 12,18 \\
y & 12,8 & 12,8 & 12,12 & 12,18 \\
z & 24,8 & 24,8 & 24,12 & 24,18 \\
\hline
\end{tabular}

To illustrate the tables, suppose the realized events for $\mathrm{ABC}$ are:

- $\quad \mathrm{y}$ in period 1 and $\mathrm{y}$ in period 2. At the end of period $1 \mathrm{ABC}$ pays a dividend equal to 12 and at the end of period 2 it pays 12 (see cell in row y, column $\mathrm{y}$ in the $\mathrm{ABC}$ table above $(12,12$ for period 1 and period 2 respectively)

- $\quad \mathrm{z}$ in period 1 and $\mathrm{x}$ in period 2. At the end of period $1 \mathrm{ABC}$ pays a dividend equal to 24 and at the end of period 2 it pays 12 (see cell in row $\mathrm{z}$, column $\mathrm{x}$ in the $\mathrm{ABC}$ table above $(24,12$ for period 1 and period 2 respectively)

or suppose the realized events for CRA are:

- $\quad \mathrm{w}$ in period 1 and $\mathrm{z}$ in period 2. At the end of period 1 CRA pays a dividend equal to 0 and at the end of period 2 it pays 18 (see cell in row w, column $\mathrm{z}$ in the CRA table above $(0,18$ for period 1 and period 2 respectively)

- $\quad \mathrm{z}$ in period 1 and $\mathrm{x}$ in period 2. At the end of period 1 CRA pays a dividend equal to 24 and at the end of period 2 it pays 8 (see cell in row $\mathrm{z}$, column $\mathrm{x}$ in the CRA table above $(24,8$ for period 1 and period 2 respectively) 


\section{APPENDIX 3 - FINANCIAL TRADING SYSTEMS PROJECT - TRADING EVALUATION FORM}

\section{Date}

Introduction

Some information has been given about trading online and the Financial Trading System (FTS). We would like your opinions about share trading before you experience the FTS game.

\section{Secret code}

We would like to generate your own unique secret code to be used in later questionnaires, which cannot be used to identify your response by anyone else. To do this, please answer the following questions:

(a) Please give the first and last letter in your mother's maiden name:

For example, if you mother's maiden name was "CHEN", enter "CN"

(b) Give the day of the month for your birthday: For example, if you were born on the $9^{\text {th }}$ of January, enter " 09 "

(c) Give the first letter of the city in which you were born:

For example, if you were born in Melbourne, enter "M"

Confidence in trading with the FTS trading system game

Listed below are activities that could be completed during financial trading with the FTS system. Please indicate how confident you feel in performing each activity by circling one number. If you are not sure of what to do or what the question refers to, please circle the " 0 ".

a) Pricing a share

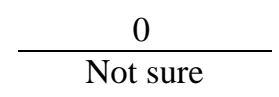

b) Setting a bid

$\frac{0}{\text { Not sure }}$

c) Setting an ask

$\frac{0}{\text { Not sure }}$

d) Buying

$\frac{0}{\text { Not sure }}$

e) Selling

$\frac{0}{\text { Not sure }}$

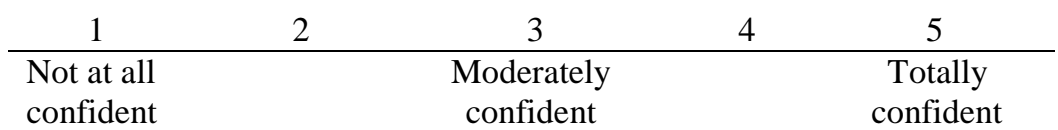

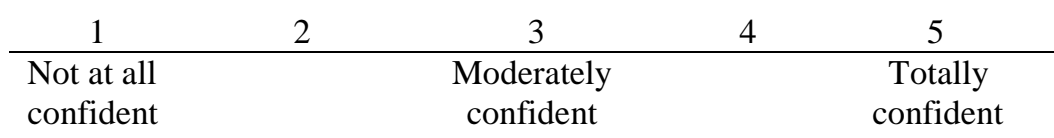

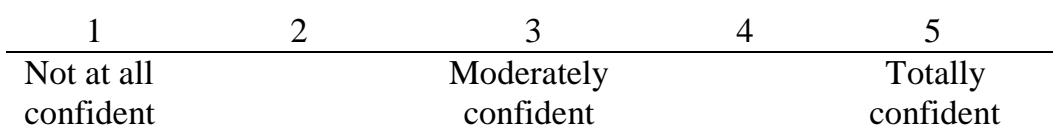

\begin{tabular}{|c|c|c|c|c|}
\hline 1 & 2 & 3 & 4 & 5 \\
\hline $\begin{array}{l}\text { Not at all } \\
\text { confident }\end{array}$ & & $\begin{array}{c}\text { Moderately } \\
\text { confident }\end{array}$ & & $\begin{array}{c}\text { Totally } \\
\text { confident }\end{array}$ \\
\hline
\end{tabular}

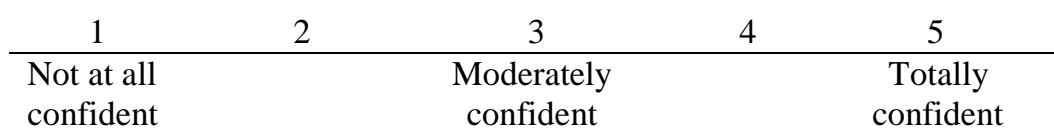




\section{FTS Stock Valuation}

Please answer the following questions about stocks $\mathrm{ABC}$.

1. For stock $A B C$, if it is state " $x$ " in the first period and state " $z$ " in the second period:

a) What is the dividend paid in period 1 ?

b) What is the dividend paid in period 2?

c) What is the value of the share in the first period?

d) What is the value of the share in the second period?

2. What is the minimum value that $\mathrm{ABC}$ can take in period 1 ?

3. What is the maximum value that $\mathrm{ABC}$ can take in period 2?

4. If you know "not $\mathrm{z}$ in period 1" for stock $\mathrm{ABC}$ what are the possible dividends that could be paid in period 1 ?

5. If the current bid and ask prices / depths are $\$ 20 / 200$ and $\$ 24 / 300$, respectively and you place a "buy" order for 200 shares what price will you pay for the shares?

6. If the current bid and ask prices / depths are $\$ 20$ / 200 and $\$ 24 / 300$, respectively and you place an ask at a price / depth of $\$ 25 / 250$ will your new ask be used if the next action in the market is a buy order for 100 shares?

7. If the current bid and ask prices / depths are $\$ 20$ / 200 and $\$ 24$ / 300, respectively and you place an ask at a price / depth of $\$ 23 / 250$ will your new ask be used if the next action in the market is a buy order for 100 shares?

\section{To Be Completed At The End Of The Tutorial After Playing The Fts Game}

\section{Confidence in trading with the FTS trading system game}

Listed below are activities that could be completed during financial trading with the FTS system. Please indicate how confident you feel now in performing each activity by circling one number. If you are not sure of what to do or what the question refers to, please circle the " 0 ".

a) Pricing a share

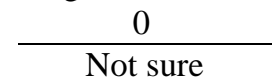

b) Setting a bid

$\frac{0}{\text { Not sure }}$

c) Setting an ask

$\frac{0}{\text { Not sure }}$

d) Buying

$\frac{0}{\text { Not sure }}$

e) Selling

$\frac{0}{\text { Not sure }}$

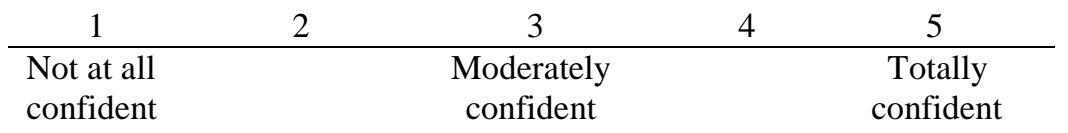

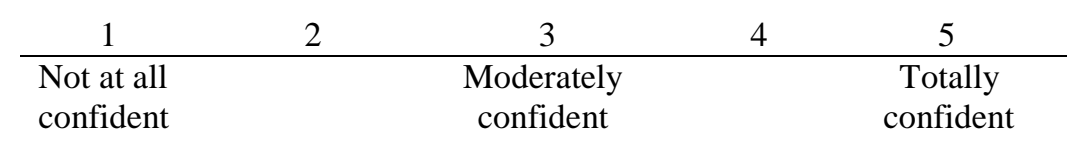

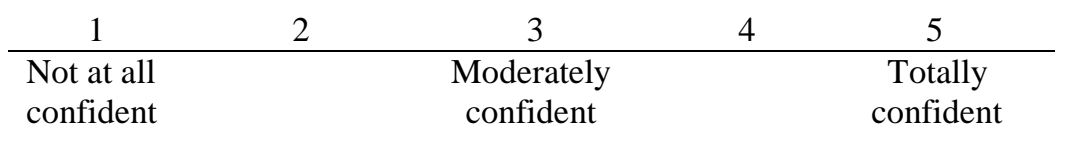

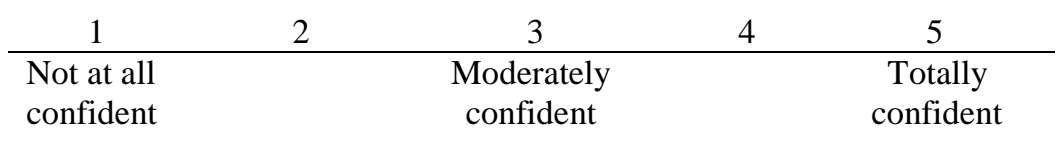

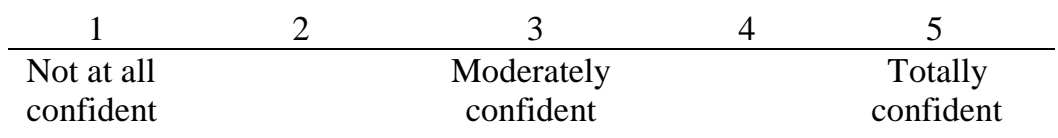




\section{FTS Stock Valuation}

Please answer the following questions about stocks $\mathrm{ABC}$.

1. For stock ABC, it is in state " $\mathrm{x}$ " in the first period and state " $\mathrm{z}$ " in the second period:

a) What is the dividend paid in period 1 ?

b) What is the dividend paid in period 2?

c) What is the value of the share in the first period?

d) What is the value of the share in the second period?

2. What is the minimum value that $\mathrm{ABC}$ can take in period 1?

3. What is the maximum value that $\mathrm{ABC}$ can take in period 2?

4. If you know "not $\mathrm{z}$ in period 1" for stock $\mathrm{ABC}$ what are the possible dividends that could be paid in period 1 ?

5. If the current bid and ask prices / depths are $\$ 20 / 200$ and $\$ 24 / 300$, respectively and you place a "buy" order for 200 shares what price will you pay for the shares?

6. If the current bid and ask prices / depths are $\$ 20 / 200$ and $\$ 24 / 300$, respectively and you place an ask at a price / depth of $\$ 25 / 250$ will your new ask be used if the next action in the market is a buy order for 100 shares?

7. If the current bid and ask prices / depths are $\$ 20$ / 200 and $\$ 24$ / 300, respectively and you place an ask at a price / depth of $\$ 23 / 250$ will your new ask be used if the next action in the market is a buy order for 100 shares?

\section{NOTES}




\section{NOTES}

